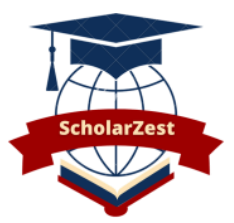

\title{
THE LEVEL OF RARITY OF RPRESENTATIVES OF THE FAMILY ALLIACEAE ON THE PREVALENCE IN THE FERGANA VALLEY
}

\author{
Foziljonov Shukrullo \\ Student of Andijan state university \\ shukrullofoziljonov@gmail.com;
}

\begin{abstract}
\begin{tabular}{|l|l|}
\hline Article history: & Abstract: \\
\hline
\end{tabular}
Received: $\quad 1^{\text {st }}$ March 2021

Accepted: $\quad 7^{\text {th }}$ March 2021

Published: $28^{\text {th }}$ April 2021

When studying each rare species of plant, the study of them on the basis of a certain order, that is, into a certain group, increases the efficiency. For example: a distributed area is a common, similar to a living environment, or a factor that multiplies in a similar way or, on the contrary, affects a decrease, etc. In this article, the generality of the families of plants was taken as a unit. The reasons for this are several: in plants belonging to the same family, basically the living environment, the distribution area and even the factor that affects the decrease will also be similar. In this work, we study the rare species of the family Alliaceae, which are distributed in the Fergana Valley.
\end{abstract}

Keywords: Red book, rare plants, Fergana valley, Uzbekistan.

\section{INTRODUCTION}

1. Oloy piyozi[uzb]-Allium alaicum[lat]-Лук алайский[rus]. Very rare endemic species of the Alay range. These species were found nearby the village Imomata, the Alay range (the Andizhan region). Inhabits soil slopes with schrubs $600 \mathrm{~m}$. s. I. 2 populations with about 50 plants were found. Limiting factors: pasturing. Measures of protection: not protected.

2. Yashil gulli piyoz[uz]-Allium viridiflorum[lat]- Лук зеленоцветковый[rus]. Very rare endemic species of the Chatkal range. These species have been recently found nearby the village Poromon, the Chatkal range (the Namangan region). Inhabits stony slopes in the lower mountain belt. Only one population (about 20 plants) was found. Limiting factors: pasturing. Measures of protection: not protected[1].

\section{MAIN PART}

\section{Allium alaicum[fig.1.]}

Brief description. Onion 1-2 cm wide, dark, papery crusty Poyasi 30-60 cm long, hairy, the lower part bent downwards. Leaves 2-3, pen-shaped, width 10-15 mm, thickly covered with feathers bent downwards, shorter than the stem. The umbrella is multi-flowered, almost spherical, 30-40 mm in diameter. Flower bands are equal, no petals. The star-shaped fragments are white, crimson, $6 \mathrm{~mm}$ long, pencil, blunt, and then bent downwards. The powder strip is $6 \mathrm{~mm}$ long, glabrous. The box is spherical in diameter $4 \mathrm{~mm}$. It blooms in June and the fruits ripen in July. Spread. Recently, Andijan region (10 km from the village of Imam-ota) south). From Uzbekistan outside Kyrgyzstan (Osh region). Growth conditions. Residue the soft soil of the mountains grows on the slopes. 


\section{European Scholar Journal (ESJ)}
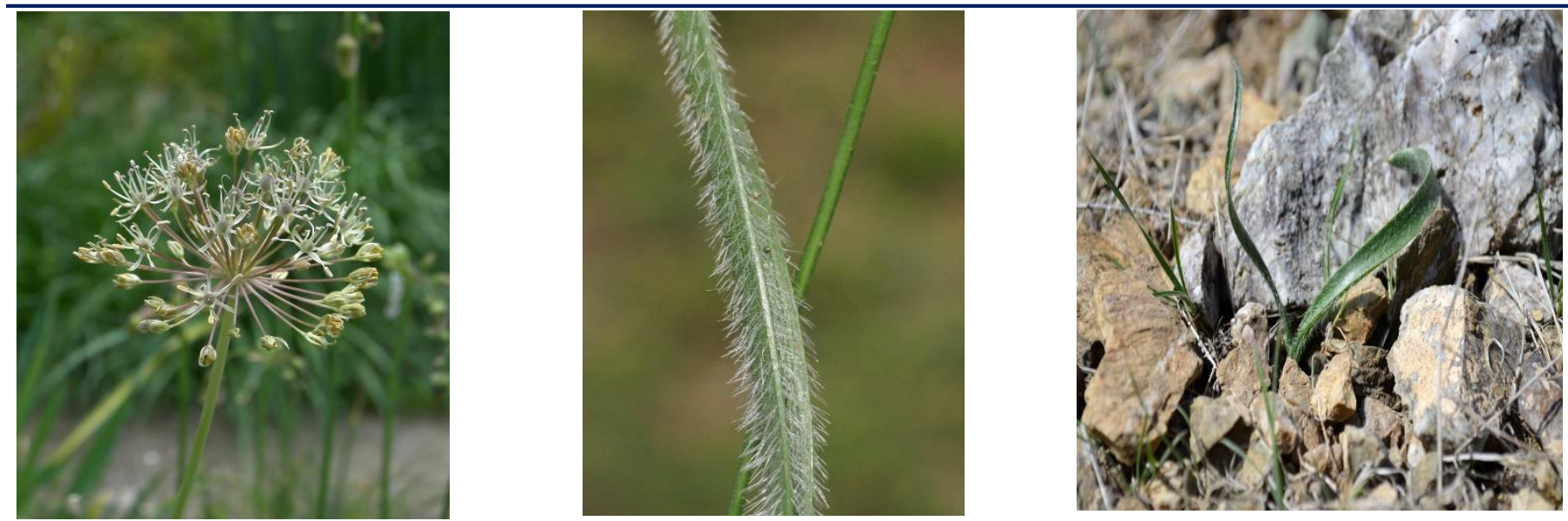

Fig.1. a.umbrella; b.leaf; c.general view

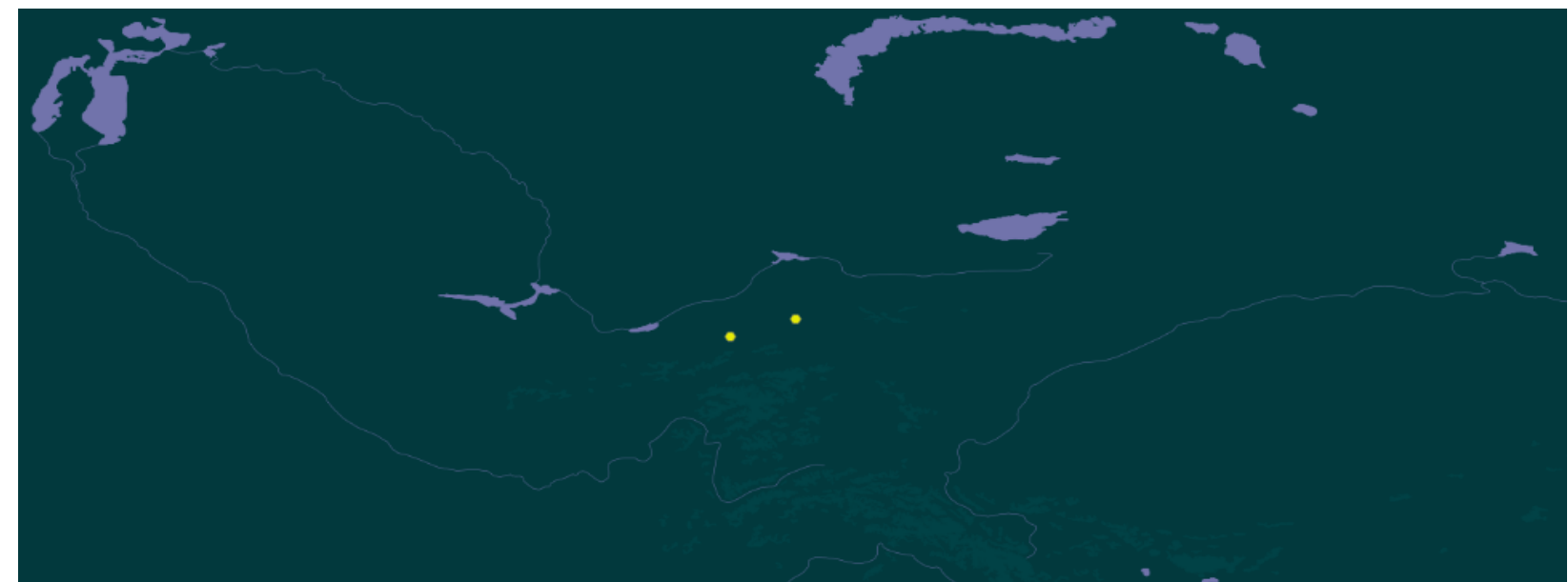

Fig.2. Species

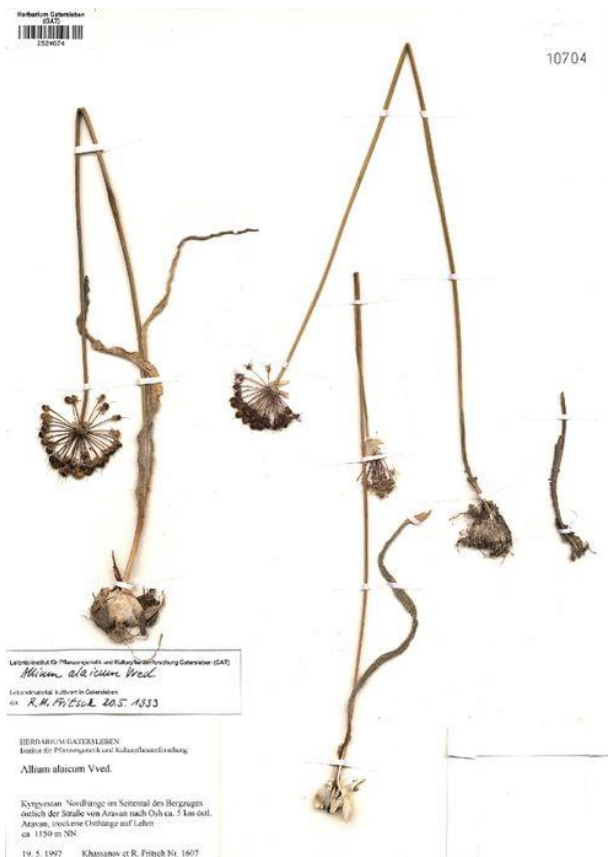

Allium alaicum Vved.

Location

Kyrgyzstan

Elevation

$1150 m$

Basis of record

Preserved specimen

Dataset

Herbarium GAT

Publisher

Leibniz Institute of Plant Genetics and Crop Plant Research (IPK)

Collection match none Institution match fuzzy 
Fig.3. Species

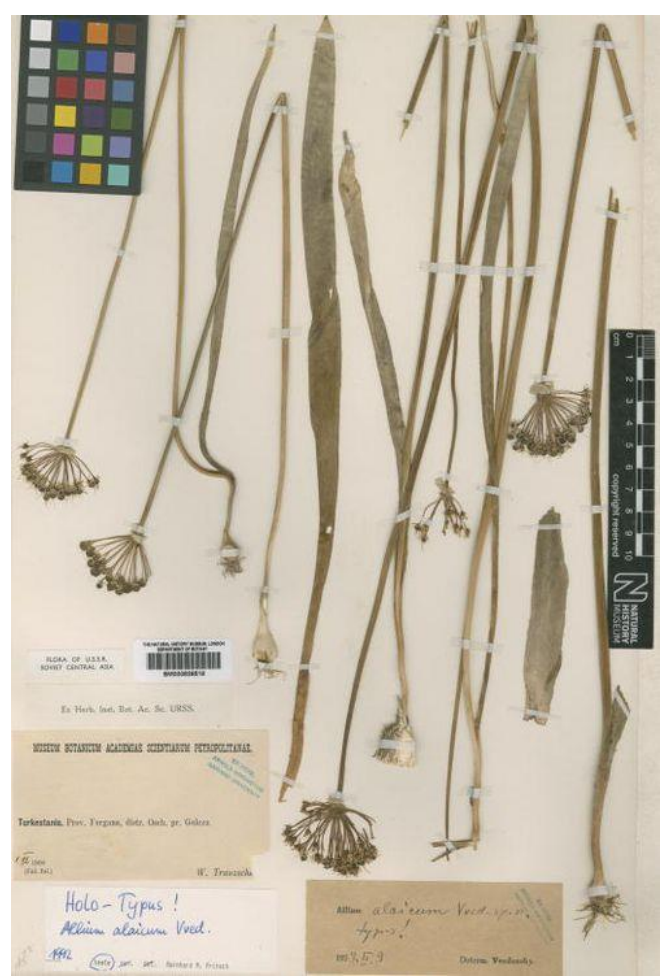

Allium alaicum Vved.

Location

Asia Uzbekistan

Basis of record

Preserved specimen

Specimen type

Holotype

Dataset

Natural History Museum (London) Collection Specimens

Publisher

Natural History Museum

Issues

Institution match fuzzy Institution collection mismatch

\section{Allium viridiflorum[fig.4.]}

Bulbs 1-2 cm wide, gray, thin-shelled. Bulbs shortened, few in number. Of the stem length $20-23 \mathrm{~cm}$, width 1.0 $\mathrm{mm}$. Leaves divided, 4-lobed, dense, The pencil has a short stalk with a pointed tip. Umbrella sparse, after flowering 7-9 cm wide. Inflorescences equal, fibrous, $4-5 \mathrm{~cm}$ long, at the base no petals, bent from bottom to top. A starshaped rose The length of the pieces is 4-5 $\mathrm{mm}$, green, equal, blunt, twisted after flowering will not remain. Powder threads shorter than a rose, basically with each other from added, toothless. A cup a little more than a rose longer, almost spherical, 3 seeded. Seeds round, black, honeycomb Spread. In 2013, from the Namangan region (2 km from the village of Poromon) on the north side). It grows in Kyrgyzstan outside of Uzbekistan. Growth conditions. In the foothills of the foothills grows.

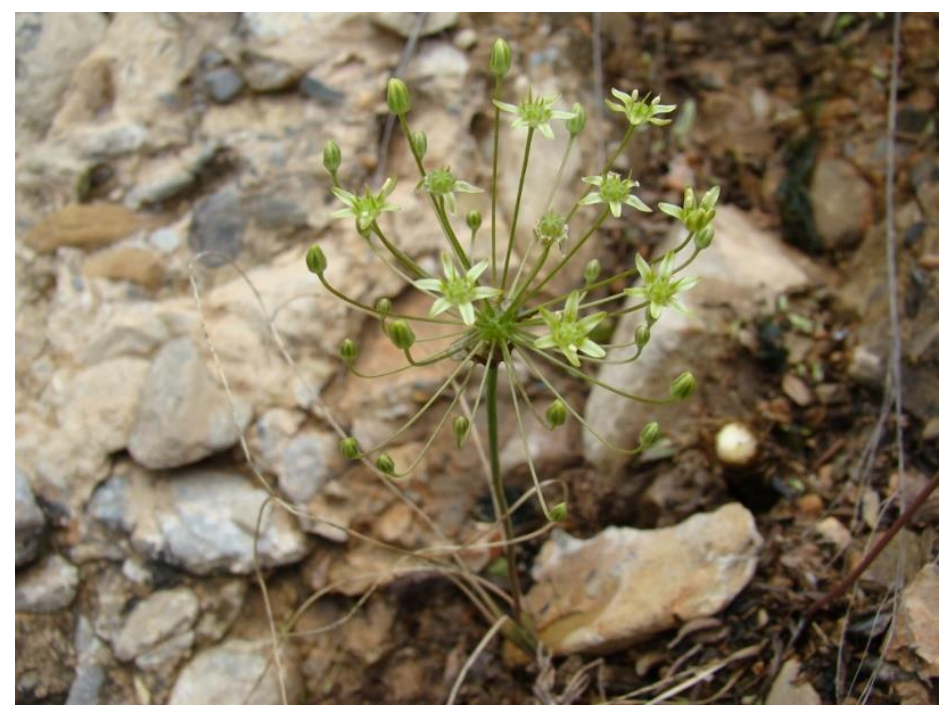

Fig.4. Flowering plant. Kyrgyzstan, Chatkal Range, Sary-Chelek Nature Reserve. June 9, 2011

Georgy Lazkov @ 2013 


\section{European Scholar Journal (ESJ)}

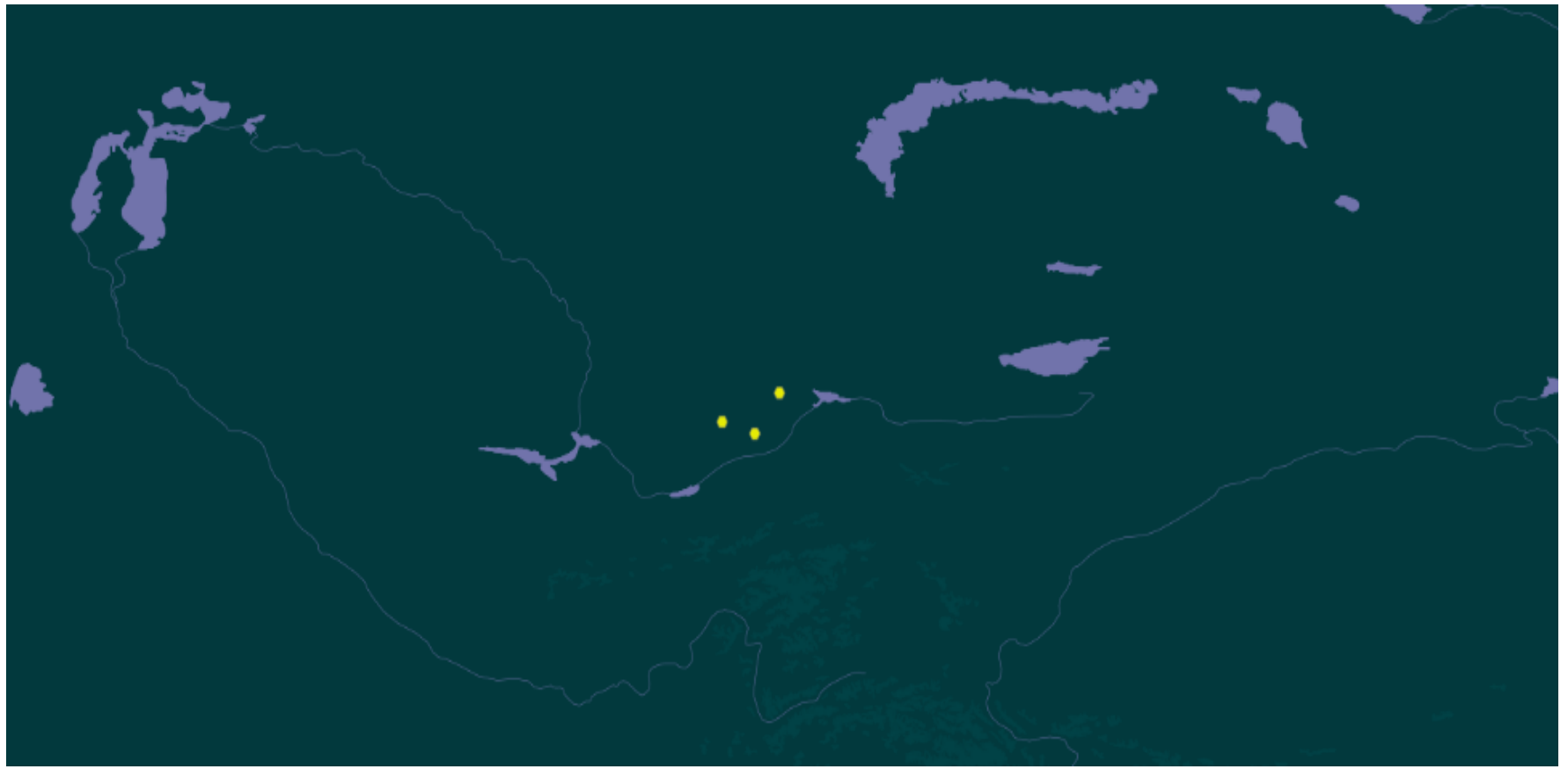

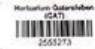

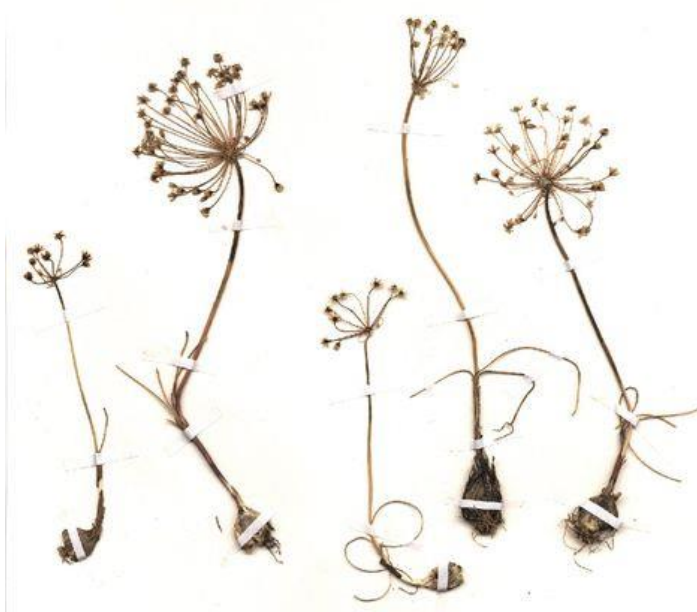

Allium viridiflorum Pobed.

Location

Kyrgyzstan

Elevation

$1400 \mathrm{~m} \pm 100 \mathrm{~m}$

Basis of record

Preserved specimen

Dataset

Herbarium GAT

Publisher

Leibniz Institute of Plant Genetics and Crop Plant Research (IPK) Issues

Collection match none Institution match fuzzy 


\author{
Allium alaicum \\ - NCBI taxonomy ID : $\underline{543647}$ \\ - PlantList-ID : kew-294927 \\ - IPNI plant ID : $\underline{527542-1}$ \\ - Tropicos ID : 18404519 \\ - Encyclopedia of Life ID : 1084221 \\ - GBIF taxon ID : 2857506 \\ - WCSPF ID : 294927 \\ - Plants of the World online ID : urn:Isid:ipni.org:names:527542-1 \\ - World Flora Online ID : wfo-0000755558 \\ - Google Knowledge Graph ID : /g/122zd92y \\ - Open Tree of Life ID : 1033447 \\ Allium viridiflorum \\ - PlantList-ID : kew-296946 \\ - IPNI plant ID : $\underline{\text { 529123-1 }}$ \\ - Tropicos ID : 18404739 \\ - NCBI taxonomy ID : $\underline{604194}$ \\ - GBIF taxon ID : 2856408 \\ - Encyclopedia of Life ID : 1085103 \\ - WCSPF ID : $\underline{296946}$ \\ - Plants of the World online ID : urn:Isid:ipni.org:names:529123-1 \\ - World Flora Online ID : wfo-0000757731 \\ - Google Knowledge Graph ID : /g/12mkyw8nb \\ - Open Tree of Life ID : $\underline{362436}$
}

\title{
REFERENCES
}

1. Red Book of the Republic of Uzbekistan, Volume 2, TASHKENT-2016

2. Red Book of the Republic of Uzbekistan, Volume 2, TASHKENT-2009

3. E. Ro'zimatov; Sh. Foziljonov., "RARE PLANT TYPES OF FERGANA VALLEY" ATLAS DICTIONARY. TOSHKENT-2021. NAVRUZ

4. Allium alaicum Vved. in GBIF Secretariat (2021). GBIF Backbone Taxonomy. Checklist dataset https://doi.org/10.15468/39omei accessed via GBIF.org on 2021-05-02.

5. Allium viridiflorum Pobed. in GBIF Secretariat (2021). GBIF Backbone Taxonomy. Checklist dataset https://doi.org/10.15468/39omei accessed via GBIF.org on 2021-05-02. 